\title{
Perceptions of Software Employees towards HRD Roles and Functions
}

\author{
${ }^{1}$ Bhagyashree Barhate, ${ }^{2}$ Malar Hirudayaraj \\ ${ }^{1}$ Research Scholar, Texas A\&M University \\ ${ }^{2}$ Assistant Professor, Department of Service System, Rochester Institute of Technology, New York \\ Email: bvtbarhate@gmail.com,malarh@gmail.com
}

Received: $20^{\text {th }}$ September 2018, Accepted: $11^{\text {th }}$ October 2018, Published: $31^{\text {st }}$ October 2018

\begin{abstract}
In order to meet the human capital needs of the organizations, human resource management (HRM) and human resource development (HRD) often work hand-in-hand [1]. Human resource departments are an integral part of any organization. These departments perform various functions such as recruitment, engagement, performance management, organizational development, training, change management, and diversity. While the concepts of HRM have been practiced in the industry for some time now, HRD is a relatively new field under the umbrella of human resources studies. Developing employees to maximize their contribution to the organization is an essential aspect of HRD. Employee training and development are key to maintaining competitive advantage in all industries, especially knowledge-based industries such as software. Constant evolution in technology, consumer needs, and global competition demand that software industries provide training and create developmental opportunities for their employees to remain competitive. However, there is no study yet that explores the perceptions of software professionals towards developmental functions within the organization undertaken by human resource professionals. This research therefore, examined the perceptions of software professionals towards HRD roles and functions in their organizations.

This research adopted a quantitative methodology and administered a survey on an online platform. The participants in this study were employed in the software industry and working in their current technical job role for at least a year. The survey was designed to include all the roles and functions described in the competency model developed by The Association of Talent Development in 2014. The survey reviewed participants' perceptions of usefulness and importance of specific HRD roles and functions. The participants ranked Learning and Knowledge Management as the most important and Change Management as most effectively managed HRD function. The results of the study indicated a general amiable perception towards HRD roles and functions.
\end{abstract}

\section{Keywords}

Human Resource Development, Perception, Software Employees

\section{Introduction}

In the software industry context and its nature, Swanson's (2009) definition of HRD is best suited - "HRD is the process of developing and unleashing expertise for the purpose of improving organization system, work process, team, and individual performance". HRD has had a long journey in terms of establishing itself as a separate field from HRM. The HR umbrella manifests both HRM and HRD functions but the HRD functions are not popularized separately and employees seldom acknowledge the presence of HRD in their organizations and often overlap their functionality with HRM. Haslinda (2009), established a distinction between HRD and HRM through definition and the processes involved in each of these functions (see Table 1).

\begin{tabular}{|c|c|}
\hline HRM & HRD \\
\hline $\begin{array}{l}\text { Definition: } \\
\text { HRM is a process of managing human talents to } \\
\text { achieve organization's objective" }\end{array}$ & $\begin{array}{l}\text { Definition: } \\
\text { HRD is a series of organized activities conducted } \\
\text { within a specified time and designed to produce } \\
\text { behavioral change }\end{array}$ \\
\hline $\begin{array}{l}\text { Process: } \\
\text { Recruitment and selection, Compensation and benefits, } \\
\text { Labor and Industrial relations, Safety \& Health } \\
\text { management }\end{array}$ & $\begin{array}{l}\text { Activities: } \\
\text { Training and development, Performance Appraisals } \\
\text { Management, Career planning and development, } \\
\text { Change Management }\end{array}$ \\
\hline
\end{tabular}

Table 1.Comparison between HRM and HRD

Rao, Rao, and Yadav (2007) [2], surveyed twelve organizations in India from the financial, consumer products, automobiles, and electronics industries, to understand the HRD function within them. The researchers found that 
less than $50 \%$ of these organizations had full-time HRD staff which made it difficult for the respondents to clearly differentiate between the HRM and HRD staff in their organization. The researchers concluded that the HRD function in these twelve organizations is "not well structured, inadequately differentiated, poorly staffed, and fails to meet the requirements of HRD frameworks" (p. 49). There is a gap in the HRD studies today as the software organizations are not yet explored to understand the

The software industry is knowledge intensive and requires its employees to be on a constant learning curve [3]. The software industry must accumulate, create, and disseminate the knowledge created within its system to develop value-added customized services for its customers [4]. New products and services through innovation are the success factors for software organizations.

With our everyday life depending on technology and applications such as Alexa, Google Home, Apple Siri, Cortana, etc., it is evident that there is no escape from technology. Satisfying customers' ever-growing technology needs and keeping up with the evolution of technology demand that software professionals constantly update their skills or develop new skillsets. The vision for continuous development in organizations can only be achieved through employee's positive perception for growth, participation, and engagement.

\section{HRD in Software}

The challenges facing the global software industry today are talent shortage, attrition, and skill-development [5][6][7]. Unraon (2018) [7] stated that to overcome shortage of competent workforce, and stay competent in the software industry, organizations must invest in HRD activities. Employee attrition is a common trend in the software industry and has been termed as 'job-hopping'. Software employees in the technical roles keep their current roles for 2-3 years before making a lateral move within the same organization or migrate from one organization to another. Agrawal and Thite (2003) [8] have attributed this trend to "voluntary attrition, reluctance to make a transition from technical to management positions, lack of managerial skills, difficulties with teamwork, work preferences, and maintaining work-family balance" (p. 1).

Due the 'job hopping' trend in the software industry which instigates employees to leave their current roles for promotions or other lucrative job offers within or outside the organization poses the challenge of employee retention and organizational commitment for HRD [9][10][7]. According to a study by Aldrin (2011) [9], 28\% participants reported that they had changed at least two organizations through their software career (p. 2).

The perceived importance and legitimacy of HRD by employees will depend on the positive support from the stakeholders, executive officers, and other senior officials [11][12]. A healthy support and perception towards HRD by the senior officials get transferred to the employees and they further perceive the importance of HRD positively. It can be said that the attitude of senior management towards HRD influences the employee perception about the importance of HRD. Senior management should also get involved in HRD actively to ensure that employees participate in the process actively.

\section{Conceptual Framework}

In 1997, Ulrich recommended the four key areas of expertise for HRD professionals were to manage strategic human resource, firm infrastructure, employee contribution, and transformation and change. With the evolution of HRD and the way organizations function, the roles and competencies of HRD in organizations has changed. The latest model describing HRD competencies has been created by the Association of Training and Development (ATD) in 2014. In order to be able to respond to different organizational challenges, HRD may have to play the role of a learning agent, trainer, training developer, change agent, consultant, etc. and should be equipped with different tools [13][11]. The ATD (2014) model is wholesome in its conceptualization of the HRD roles and functions. It recognized ten essential areas of expertise and six foundational competencies required in HRD (see Figure 2)

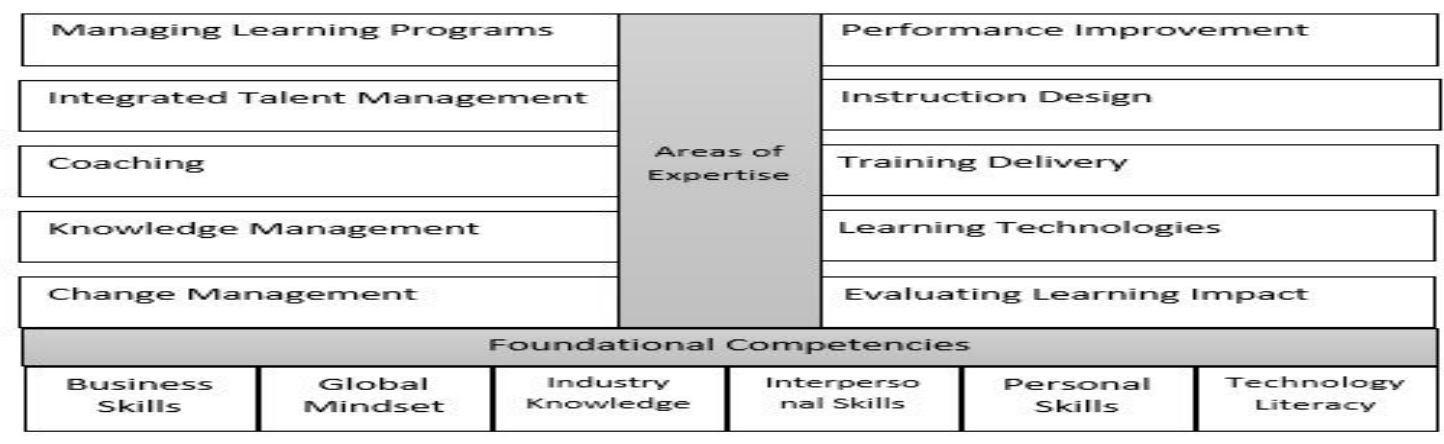


Figure 1. The ATD Competency Model (2014). Adapted from The ATD Model (2014). Source: https://www.td.org/Certification/Competency-Model

\section{Materials and Methods}

The purpose of this study was to understand the perceptions of software employees towards HRD roles and functions as HRD is not always separated from the HRM roles and functions in the organizations. Ten HRM roles and functions to establish a distinction between HRM and HRD roles and functions. The HRM roles and functions were - Performance Management/Appraisal, Rewards and Recognition, Career Development, Conflict Resolution, Benefits and Compensation, Employment Laws and Compliance, Payroll, Hiring/Recruitment/Talent Acquisition, Procedural Justice (fairness in the processes) and Distributive Justice (fairness associated with outcome, decisions, and distribution of resources), Training. The roles were selected based on the frequency of their occurrence in the research published by HRM scholar-practitioners.

The research required that the participants be working in a technical role in the software industry for at least one year. The technical employees are usually engrossed in their client projects and rarely have time to engage in the organization's activities unless made mandatory. The participants were recruited from India and the U.S. mainly based on the personal contact of the researchers. The participants were initially contacted through personal emails, messaging via social media such as Facebook and LinkedIn. The participants were also requested to forward the link to the survey to their friends and colleagues thus initiating a snowball sampling method. Further, the researcher also contacted the alumni who had graduated from the Department of Computer Science, Information technology, Computer security, and Software Engineering at Rochester Institute of Technology.

The study used a cross-sectional survey design to collect the perceptions of software professionals. The survey was designed on an online platform - Google forms. According to Haslinda (2009) [1], employees often find it a challenge to differentiate between HRM and HRD roles and thus the survey was designed in a way that it provided distinct functional distinctions between HRM and HRD.

The survey had a total of 26 questions and was divided into three separate sections. The first section of the survey collected participant demographic information and included questions such as country of employment, the name of the company, job role, and length of service in software. In the second section, participants were asked to rank ten HRM roles and functions in the order of their perceived importance. The weight for ranking was from 1-10 with 1 signifying the highest rank and 10 the lowest. In the same section, the participants were asked another question to rank six HRD roles and functions in the order of their perceived importance. The weight for ranking was from 1-6 with 1 signifying the highest rank and 6 the lowest.

The survey used in this research included questions based on these 10 areas of expertise and 6 foundational competencies expected in the HRD professionals. The areas of expertise were either clubbed or diffused to form the survey questions (see Table 2).

\begin{tabular}{|c|c|c|}
\hline \multirow[t]{2}{*}{ ATD competencies } & \multicolumn{2}{|l|}{ Design of Question } \\
\hline & $\begin{array}{l}\text { Rank in terms of perceived } \\
\text { importance }\end{array}$ & State the perceived effectiveness \\
\hline $\begin{array}{l}\text { Knowledge Management } \\
\text { Change Management } \\
\text { Integrated Talent Management } \\
\text { Coaching } \\
\text { Performance Improvement }\end{array}$ & $\begin{array}{l}\text { Learning and Knowledge } \\
\text { Management } \\
\text { Change Management } \\
\text { Talent Management } \\
\text { Coaching and Mentoring } \\
\text { Performance Improvement }\end{array}$ & $\begin{array}{l}\text { Learning and Knowledge Management } \\
\text { Change Management } \\
\text { Talent Management } \\
\text { Coaching and Mentoring } \\
\text { Performance Improvement }\end{array}$ \\
\hline $\begin{array}{l}\text { Instructional Design } \\
\text { Training Learning } \\
\text { Evaluating Learning Impact } \\
\text { Learning Technologies } \\
\text { Managing Learning Programs }\end{array}$ & - Training & $\begin{array}{l}\text { Design of Training } \\
\text { Delivery of Training } \\
\text { Evaluation of Training programs } \\
\text { Training Feedback } \\
\text { Use of Technology in Training } \\
\text { Co-ordination of Training } \\
\text { Contribution to Career Growth }\end{array}$ \\
\hline
\end{tabular}




\section{Table 2.Using ATD Areas of Expertise to Design the Survey Questions}

The third and last section included questions to evaluate the level of satisfaction of the participants towards the effectiveness of HRD roles and functions performed in their organizations. This section had a total of fourteen Likert-scale based questions. The Likert-scale had scores from 1-5 with 5 being the highest satisfaction and 1 being the lowest. The score 1 corresponded to 'Strongly Disagree', 2 corresponded to 'Disagree', 3 corresponded to 'Neutral', 2 corresponded to 'Agree', 5 corresponded to 'Strongly Agree'.

\section{Results and Discussion}

A total of 104 responses were received for the survey however, 100 responses were considered valid and 4 responses had to be discarded due to incomplete responses and same participants responding multiple times. The response data was analyzed using descriptive statistics using percentages, ratios, averages, tables, and bar graphs. The study was focused on understanding the perceptions of software employees and did not have any dependent variables.

Upon analysis of the data, it was found that $32 \%$ participants perceived performance management/appraisal as the most important HRM role and function which corroborates with the consensus around the perception of this role in organizations today. Performance management/appraisal has been termed as the 'Achilles' heel' in HRM [14] and can cause employee contentment or discontentment towards the organization. A study conducted by Pulakos (2004) [14] about the employee perceptions about HRD roles also illustrated that performance management/appraisal is the most important HRM role and function.

It was found that the participants voted Learning and Knowledge management as the most important HRD role and function. According the Association of Talent Development (2014), learning and knowledge management is the process to, "capture, distribute, and archive intellectual capital to encourage knowledge-sharing and collaboration". The process of learning and knowledge management is a continuous process and requires employee's engagement for its effective performance and implementation. A rigorous database of employee's completed learning programs is maintained by HRD aiding in employee's structured career development. The software employees work in an incentive-based system where their high achievements and client satisfaction are highly rated during their performance management/appraisal. For them to rate learning and knowledge management as the most important HRD role and function is an indication that they want the HRD department to manage their learning and achievements which increase their skill sets and thus making them marketable in the industry.

The rankings of other roles and functions have been represented in the bar chart below.

\section{Ranking of HRD Functions}

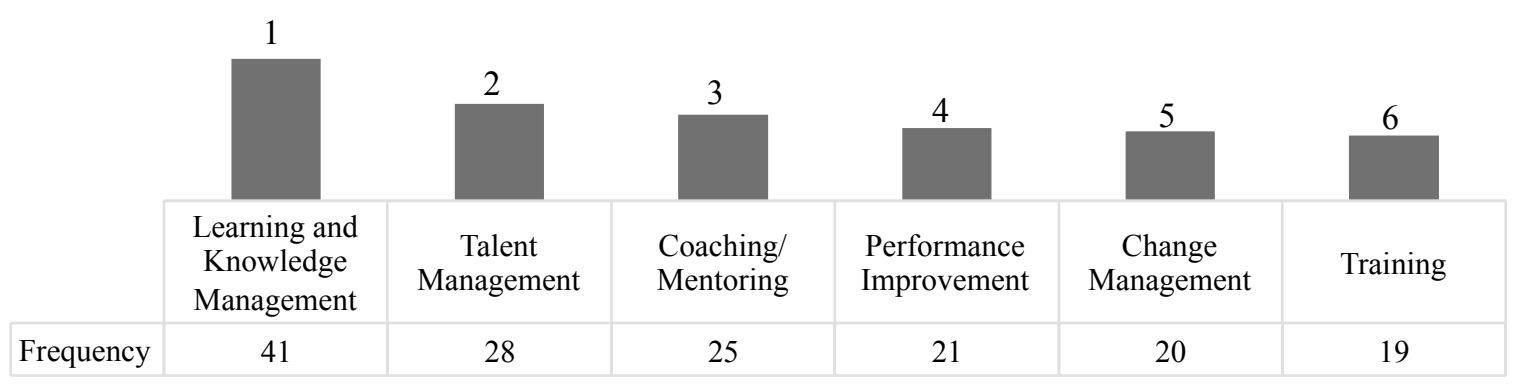

The HRM role and function, performance management/appraisal deals with incentivizing employee performance, whereas the HRD role and function of performance improvement is a process of goal setting and optimizing processes for the organization's profitability [15]. About 40\% of participants were satisfied with the effectiveness of performance improvement in their organizations. The HRD department can assist the employees in goal setting to meet the employee's career goals and tie them to the organization's goals. About 34\% of the participants responded that they did not have any opinion on this function and $26 \%$ participants were dissatisfied with it which leads to the belief that the employee's direct or line managers are not engaged in the goal setting process. Another cause may also be attributed to the nature of the software industry where the employees are given team tasks as opposed to individual tasks and thus the goals are communal in nature. When the client project is a success, the team is regarded as successful. The HRD department can assist individual employees to understand their skill sets through an 
investigative performance improvement process and thus assigned to the projects that in alignment with the employee's developmental needs.

The HRD department can assign a coach or a mentor to the employees to further aid in personal and professional development. Forty percent of participants were satisfied with the coaching/mentoring function in their organizations whereas, $28 \%$ were dissatisfied. Coaching and mentoring are most effective if performed by the direct supervisors or line managers [16]. Thirty-two percent participants had no opinion on this function as they may have never experienced it and thus have no perception of it. The most common reasons to be appointed a coach or a mentor are when the employee is new at their job or is getting ready for a higher position within the organization. Coaching and mentoring and learning and knowledge management are important forms of talent management within the organization to make sure that skilled and employees that are highly desirable by the organization are retained and not lost to the 'job-hopping' trend.

Forty-two percent of participants were satisfied with how talent management was performed in their organization, whereas $26 \%$ were dissatisfied. In software organizations, talent management is usually performed through a systematic implementation of human resource information system (HRIS) where employees can maintain a record of their skills and update them whenever needed [17][18]. The HRIS system is accessed by all the employees within the organization and gives high visibility of employee skills to project managers who are looking for new team members in their client project. However, there still were 32\% participants who did not have any opinion on the effectiveness of talent management in their organizations.

Change management is a function that is performed on a regular basis in all organizations. However, how involved employees are usually depends on the scope of the change activity. The ATD (2014) defines change management as "apply a systematic process to shift individuals, teams, and organizations from current state to desired state". In a research by Alagaraja and Egan (2013) [19], it was concluded that employees are often unaware of the change management activities undergoing in the organization. This research corroborated with Alagaraja and Egan's (2013) [19] findings as $42 \%$ participants had no opinion and $21 \%$ participants were dissatisfied about the effectiveness of change management.

"Training and development constitute the largest realm in HRD" [16]. In contrast to all other HRD roles and functions, training and development was rated as the most effectively performed HRD role and function recording $48 \%$ agreement. Training and development is the most familiar HRD role and function among employees as it is a formal and informal process of knowledge gathering and implementing. All employees undergo training be it at the beginning of their job, during a job transfer, process change, to use new technology, and to use different computer languages. In a study conducted by Ofori (2012), training and development was ranked as the most important HRD role and function in Ghana whereas the participants in this study ranked it sixth. The participants here may not have ranked training and development as the most important HRD role and function but they certainly perceive its performance as effective.

The results of this study show that the employees overall have an amiable attitude towards the HRD roles and functions. However, the literature from past studies has shown that employees in organizations may not be consciously aware of the HRD roles and functions that are being performed by the HR department. With this study, the participants were exposed to the difference between HRM and HRD and it provoked them to think about the importance and effectiveness of HRD roles and functions in their organizations. Outside of the participants of this study, it is worthwhile to have the software employees understand that the HRD roles and functions are meant to aid in their personal and professional growth. The change in employee's perceptions will make them open to engaging in the HRD activities performed by the organizations.

\section{Conclusion}

As a practitioner or scholar within the HR umbrella, it is important to understand employee perceptions so that the HRD practices and research can be customized to meet the employee and organizational needs. The participants of this study were able to respond about their perception towards the different HRD roles and function because of their personal interactions with the HR department. In the future, a qualitative inquiry will be worthwhile where the participants can be interviewed about their individual experiences with the HRD roles and functions. The qualitative data will be able to provide subjective perceptions leading the practitioners to improve their current professional practices.

Current research shows that HRD is not considered a strategic partner by organizational leadership and thus the HRD practices take a back-seat in the organization's agenda [19]. A strong support from the employees at the managerial level will give the HRD department freedom to engage in employee development activities on a larger scale which can also help in building healthy employee perceptions. The findings in this study indicate that 
employees have a better perception of the HRD roles and functions that are effectively performed such as learning and knowledge management. The HRD roles and functions may differ from industry to industry and it is worthwhile to understand them before designing HRD interventions for employee and organizational development.

\section{References}

[1] Haslinda A. Evolving terms of human resource management and development. The Journal of International Social Research, 180-186, Vol:2, 2009.

[2] Rao TV, Rao R, Yadav T. A study of HRD concepts, structure of HRD departments, and HRD practices in India, Vikalpa, 49-63, Vol:26, 2001.

[3] Mei WCW, Subramaniam ID. A comparison of the ability level of human resource roles and their perceived importance among HR professionals in the Malaysian Government linked companies Canadian Center of Science and Education, Vol:10, 2014.

[4] Bettencourt LA, Ostrom AL, Brown SW, Roundtree RI. Client co-production in knowledge-intensive business services, California Management Review, Vol:44, 2002.

[5] Cho Y, McLean G. Leading Asian countries HRD practices in the IT industry: A comparative study of South Korea and India, Human Resource Development International, 313-331, Vol:12, 2009.

[6] Rao TV, Varghese S. Trends and challenged of developing human capital in India, Human Resource Development International, 15-34, Vol:12, 2009.

[7] Unraon RS. Examining the impact of HRD practices on organizational commitment and intention to stay within selected software companies in India, Advances in Developing Human Resources, 11-43, Vol:20, 2018.

[8] Agrawal NM, Thite M. Human resources issues, challenges, and strategies in the Indian software industry. International Journal of Human Resource Development and Management, 248-264, Vol:3, 2003.

[9] Aldrin R. A study on human resource management in ITeS companies-problems and prospects (Masters Thesis). (2011).

[10] Tambe P, Hitt LM. Job hopping, information technology spillovers, and productivity growth. Management Science, 338-355, Vol:60, 2014.

[11] Gubbins MC, Garavan TN. Studying HRD practitioners: A social capital model. Human Resource Development Review, 189-218, Vol:4, 2005.

[12] Gubbins C, Garavan TN, Hogan C, Woodlock M. Enhancing the role of the HRD function: The case of a health services organisation. Irish Journal of Management, 171-206, Vol:27, 2006.

[13] Gilley and Maycunich. Strategically integrated HRD. 2003.

[14] Pulakos. Performance management: A new approach for driving business results, 2009.

[15] Dubois and Rothwell. Competency-based Human Resource Management. 2004

[16] Swanson and Holton. Foundations of Human Resource Development. 2009.

[17] Accenture | Strategy, Consulting, Digital, Technology and Operations. (n.d.).

[18] Spreitzer G, Porath, C. Creating sustainable performance. Harvard Business Review. (2012).

[19] Alagaraja M, Egan T. The Strategic Value of HRD in Lean Strategy Implementation, Human Resource Development Quarterly, 1-27, Vol:24, 2013. 